Broadwater, K., Curtin, L., Martz, D.M., \& Zrull, M.C. (2006). College student drinking: Perception of the norm and behavioral intentions. Addictive Behaviors, 31(4): 632-640. (Apr 2006) Published by Elsevier Science Limited (ISSN: 1873-6327).

\title{
College student drinking: Perception of the norm and behavioral intentions
}

Kelly Broadwater, Lisa Curtin, Denise M. Martz, and Mark C. Zrull

\begin{abstract}
Social norm campaigns assume that college students desire to increase their drinking, and may eventually do so, to match inflated perceptions of peer drinking. We assessed 171 college students on self-reported drinking, desired drinking and perception of peer drinking at baseline, and assessed 139 of those students one month later. Participants who believed their peers drank more than they were hypothesized to desire to increase their alcohol consumption to match the perceived norm. This hypothesis was not supported; however, 91\% of participants believed their peers drank more than themselves. It was also hypothesized that participants who wished to drink more would drink more in the future. Participants who desired to increase their drinking did not report a significant change in drinking behavior one month later, but participants who initially desired to maintain or decrease their drinking reported significant decreases across the following month. College student overestimation of peer drinking and the college environment are discussed. Social norm campaigns should consider behavioral intentions, and the underlying assumptions of these campaigns should be further tested.
\end{abstract}


College student alcohol consumption is a significant public health problem (Ham \& Hope, 2003). Over $80 \%$ of college students report drinking alcohol (Johnston, O'Malley, Bachman, \& Schulenberg, 2004), and about 40\% report a heavy drinking episode in the previous two weeks (O'Malley \& Johnston, 2002 and Wechsler et al., 1994). Heavy episodic drinking (typically defined as at least four or five drinks in a single sitting) among college students is associated with poor academic performance, legal problems, risky sexual behaviors, and alcohol-related injuries and deaths (Hingson et al., 2002 and Perkins, 2002a). Lowering the proportion of students engaging in heavy drinking is an objective of the Surgeon General's national health promotion and disease prevention initiative (Department of Health and Human Services, 2000).

College students tend to overestimate the quantity and frequency of their peers' alcohol consumption (Baer \& Carney, 1993 and Perkins et al., 1999). In addition, college students reliably believe their peers consume more alcohol than themselves (Borsari \& Carey, 2003), and perceptions of normative college student drinking correlate positively with personal alcohol consumption (Baer \& Carney, 1993, Baer et al., 1991, Perkins \& Berkowitz, 1986 and Perkins \& Wechsler, 1996). College student overestimation of peer drinking behavior may contribute to a heavy drinking environment by justifying heavy personal drinking behavior, and/or guiding personal drinking behavior (e.g., perceived pressure to match normative drinking).

In recent years, social norm campaigns have been implemented and tested on college campuses across the country (Haines \& Spear, 1996 and Wechsler et al., 2003). Social norm campaigns use posters, public service announcements, advertisements, flyers and pamphlets to convey survey results of average campus drinking behaviors in a positive manner (e.g., more than half of students drink five or fewer drinks when partying). Dissemination of accurate information about campus drinking behavior intends to decrease the perception of a heavy drinking environment, normalize less heavy drinking behavior, and decrease perceived pressure to drink among college students. A number of uncontrolled longitudinal studies of social norm campaigns (e.g., Haines \& Spear, 1996 and Johannessen et al., 1999) found decreases in the perception of campus heavy drinking and corresponding decreases in self-reported student drinking. However, some quasi-experimental investigations found decreased perceptions of peer drinking, but no change in drinking behavior and some evidence of increased drinking associated with social norm programs (Clapp et al., 2003, Wechsler et al., 1994 and Wechsler et al., 2003).

Despite the widespread implementation of social norm campaigns, little is known about how normative campaigns might work and some researchers caution college campuses from widescale acceptance and implementation of social norm campaigns until the underlying mechanisms are better understood (Trockel et al., 2003 and Wechsler et al., 2003). One assumption of social norm campaigns is that college students perceive their peers as heavy consumers of alcohol, and in turn, may increase personal drinking to match the perceived drinking norm (DeJong, 2002 and Trockel et al., 2003). Overestimating peer drinking may relate to a desire to increase personal drinking in the future. Indeed, Sherman, Presson, Chassin, Corty, and Olshavsky (1983) found a significant positive relationship between adolescents' estimates of smoking prevalence and intentions to smoke in the future. However, little is known about the drinking intentions of college students. In a recent study, over half of a sample of 128 
college students wished they drank an average of 6.22 more drinks per week (Curtin et al., 2000 L. Curtin, J. Gaukstern and D.M. Martz, College student drinking: A test of Bandura's model of self-regulation, Poster presented at the annual meeting of the Association for the Advancement of Behavior Therapy, New Orleans, LA (2000, November).Curtin, Gaukstern, \& Martz, 2000). In turn, intentions to increase drinking may relate to future drinking. For example, Glindeman, Geller, and Ludwig (1996) found drinking intentions prior to a fraternity party predicted postparty intoxication.

The relationship between perceptions of peer drinking and personal behavioral intentions has not been assessed with regard to college student drinking, even though positive norm campaigns are thought to decrease college student drinking by correcting perceptions of exaggerated normative drinking. In the present study, we assessed perceptions of normative drinking among close friends, drinking intentions, and self-reported college student drinking at an initial assessment and one month later. We hypothesized that: 1) participants who believed their close friends drank more than they would desire to increase their alcohol consumption to match what they considered normative behavior; and 2) participants who reported a desire to increase drinking would do so across the next month.

\section{METHOD}

\section{Participants}

One hundred seventy-one undergraduate students (70 males, 101 females) from a middlesized, southeastern university who consumed alcohol participated in the study. The mean age of the sample was 18.66 years (S.D. = 1.60). The sample consisted of mostly freshmen (80.1\%), students living on campus (83.6\%), and students who were not involved with campus fraternities or sororities (88.3\%). All participants were single and most were Caucasian (98.2\%).

A one-month follow-up was conducted with 139 of the original 171 participants (81\%; 56 males, 83 females). Participants were on average 18.68 years of age (S.D. = 1.69), and were again primarily freshmen (79.9\%), living on campus (84.2\%), not involved with Greek organizations (87.8\%), and Caucasian (97.8\%). At baseline, participants who attended the one-month followup ( $n=139)$ did not differ from participants who did not attend the follow-up $(n=32)$ on average weekly self-reported drinking, $t(169)=-.09, p=.93$ or perceptions of peer average weekly drinking, $t(169)=-.67, p=.51$.

\section{Measures}

The Time-Line-Follow-Back method (TLFB; Sobell, Sobell, Klajner, Pavan, \& Basian, 1986) assessed self-reported quantity and frequency of alcohol consumption as well as desired quantity and frequency of drinking. We customized a calendar with holidays and campus/community events to help participants recall how many standard drinks they consumed each day for the previous month. One drink was defined as twelve ounces of beer, five ounces 
of wine, or one ounce 86-100 proof liquor. The TLFB has adequate test-retest reliability with college students over 30 days (r's ranging from .76 to .96).

The Drinking Norms Rating Form (DNRF; Baer et al., 1991) assessed participants' estimates of peer drinking. This questionnaire asks participants to estimate the number of drinks their "immediate group of close friends" consumed each day for an average week during the past month. A specific reference group rather than a general reference group (e.g., average student) was used because self-other discrepancies are generally less inflated (Borsari \& Carey, 2003). Previous studies assessing college student perceptions of alcohol use have used the DNRF, suggesting face validity and predictive utility (Baer et al., 1991, Kypri \& Langley, 2003 and Larimer et al., 1997). The test-retest reliability of the DNRF in the present study was .69.

\section{Procedure}

Undergraduate participants who drank alcohol were recruited from general psychology classes in exchange for research credit. Following written informed consent, participants completed two TLFB forms. The first TLFB calendar included instructions to report the daily number of drinks actually consumed each day across the previous month. The second TLFB calendar included instructions to report the number of drinks the participant wished he/she consumed (desired) each day across the same month. The DNRF was then completed to assess participants' perception of peer drinking.

Following the initial assessment (Time 1), participants were asked to schedule a one-month follow-up (Time 2). Participants received a reminder phone call prior to their scheduled return date. At this time, they again completed the TLFB twice, reporting actual and desired drinking for the month following the initial assessment, and completed the DNRF.

\section{Approach to analyses}

Average weekly self-reported drinking and average weekly desired drinking were computed from the TLFB at both assessment points by summing the daily number of drinks reported for the previous 28 days and dividing by four. Perceptions of peer average weekly drinking were computed by summing participant reports of close friends' daily drinking across an average week from the DNRF at Time 1 and Time 2.

The first hypothesis proposed that participants who believe their close friends drink more than they would desire to increase their alcohol consumption. The difference between perception of peer drinking and participant self-reported drinking was computed for each participant and this difference score was used to create two levels of a quasi-independent variable: 1) perception that peers drink more than participant self-reported drinking at Time 1 and 2) perception that peers drink an equivalent amount or less than participant self-reported drinking at Time 1 . The dependent variable was the difference between desired drinking and actual drinking with positive numbers indicating a desire to drink more. 
The second hypothesis proposed that participants who desired to increase their drinking during the initial assessment would do so across the following month. The difference between desired and actual drinking during the initial session was computed for each participant, and was used to create two levels of a quasi-independent variable: 1 ) desire to drink more than self-reported drinking during the initial session; and 2) desire to drink the same or less than self-reported drinking during the initial session. The dependent variable was the difference between participant self-reported drinking at Time 2 and participant self-reported drinking at Time 1 with positive numbers indicating increased drinking at Time 2 relative to Time 1.

\section{RESULTS}

One hundred seventy-one participants completed the TLFB and DNRF during the initial assessment session, and 139 participants returned for the one-month follow-up assessment. Average self-reported levels of weekly alcohol consumption, $t(138)=2.95, p=.004$, decreased significantly between Time $1(M=13.65$, S.D. $=10.20)$ and Time $2(M=12.17$, S.D. $=9.75)$. Mean perceptions of weekly peer drinking, $t(138)=4.20, p=.001$, decreased significantly between Time $1(M=28.75$, S.D. $=18.96)$ and Time $2(M=23.76$, S.D. $=15.90)$, and average desired drinking decreased significantly between Time $1(M=13.92$, S.D. $=11.40)$ and Time 2 $(M=12.11$, S.D. $=9.66), t(138)=2.99, p=.003$. All correlations between actual weekly drinking, desired weekly drinking, and perceptions of peer drinking within and across the two time points were significant and between 0.59 and $0.84(p<0.01$ for all).

An Analysis of Variance (ANOVA) was employed to compare participants who believed their peers drank more than themselves $(n=156)$ to participants who believed their peers drank an equal amount or less than themselves $(n=15)$ on differences between desired drinking and actual drinking at Time 1. Counter to hypothesis, the two groups did not differ from each other on the difference between desired and actual drinking assessed at Time $1, F(1,169)=.03$, $p=.87, \eta^{2}=.001$.

The second hypothesis was tested with the 128 participants who believed their peers drank more than they do and returned for the second assessment. Participants who desired to drink more at the initial assessment $(n=58)$ were compared to participants who desired to drink the same or less at the initial assessment $(n=70)$ on the difference between Time 2 self-reported drinking and Time 1 self-reported drinking, $F(1,126)=11.46, p=.001, \eta^{2}=.083$. Recall positive numbers indicate an increase in self-reported drinking at Time 2 relative to Time 1 . Participants who desired to drink more at Time 1 reported an average difference between Time 2 and Time 1 drinking of 0.55 drinks (S.D. $=5.38$ ), and participants who desired to maintain or decrease their drinking at Time 1 reported an average difference between Time 2 and Time 1 drinking of - 2.55 drinks (S.D. = 4.95). Counter to hypothesis, participants who reported a desire to increase their drinking did not significantly change their alcohol consumption across time, $t(57)=-.78, p=.44$; whereas participants who desired to drink the same or less decreased their alcohol consumption significantly across time, $t(69)=4.31, p=.001$. Participants who desired to drink more at Time 1 reported drinking less at baseline $(M=11.29$, S.D. $=8.66)$ than 
participants who desired to maintain or decrease their drinking at Time $1(M=14.89$, S.D. $=10.24), F(1,126)=4.52, p=.036, \eta^{2}=.035$

Drinking desires remained relatively stable across time. Of the 58 participants who desired to increase their drinking at Time 1, 67.2\% $(n=39)$ continued to report a desire to increase their drinking at Time 2. Of the 70 participants who reported a desire to maintain or decrease their drinking at Time 2, 67.1\% $(n=47)$ continued to desire to maintain or decrease their drinking at Time 2. Participants who desired to drink more at Time 1 had significantly greater differences between desired Time 2 drinking and actual Time 2 drinking $(M=1.99$, S.D. $=4.98$; positive numbers indicate a desire to drink more than currently drinking at Time 2) than participants who desired to maintain or decrease their drinking at Time $1(M=-1.64$, S.D. $=5.24), F(1$, 126) $=15.93, p=.001, \eta^{2}=.112$.

\section{DISCUSSION}

The present study assessed college students' perceptions of their close friends' alcohol consumption, and how those perceptions related to personal drinking intentions and future drinking behavior. Ninety-one percent of participants believed their close friends drank more alcohol than themselves. On average, participants who desired to maintain or decrease their drinking at the initial assessment reported significant decreases in self-reported drinking at the second assessment relative to the first assessment, but contrary to hypothesis, participants who desired to increase their drinking at the initial assessment did not report significant drinking changes from Time 1 to Time 2 .

Similar to previous findings (Baer \& Carney, 1993, Perkins \& Berkowitz, 1986 and Perkins et al., 1999), the overwhelming majority of participants (91\%) thought their "immediate group of close friends" drank more than themselves. The present study, however, found a larger mean discrepancy between participant self-reported drinking and perception of peer drinking than other studies. Assessment of peer drinking perception in this study focused on the participants' immediate group of close friends given that the meta-analytic review of Borsari and Carey (2003) found that self-other discrepancies were greater for general reference groups than for specific reference groups. Our potentially exaggerated view of normative drinking may be partially accounted for by the fact that we excluded abstainers. Further, our sample consisted of mostly first semester freshmen and students living on campus, both of which are related to heavy drinking (Engs et al., 1996, O'Hare, 1990 and Turrisi et al., 2000), and likely allow for limited opportunities to challenge potential misperceptions. Finally, self-other discrepancies of drinking behavior may be greater for females than for males, and greater on smaller compared to larger college campuses (Borsari \& Carey, 2003). Our sample consisted of somewhat more females (nearly 60\%) than males, and our data was collected on a medium sized campus of approximately 13,000 students.

Desire (intention) to drink related positively with concomitant and future self-reported drinking in correlational analyses, and remained stable across time for about two-thirds of participants. Our longitudinal study found that, on average, participants who desired to maintain or decrease 
drinking behavior significantly decreased drinking across time. On the other hand, participants who desired to increase drinking at the initial assessment did not significantly change their selfreported drinking between Time 1 and Time 2. The stability in drinking for participants initially wishing to increase drinking, and the decrease in drinking for participants initially wishing to maintain or decrease drinking, may represent reactivity to self-assessment (Cronin, 1996 and Larimer \& Cronce, 2002), naturalistic decreases in drinking across the course of the semester in relation to environmental variables (DelBoca, Darkes, Greenbaum, \& Goldman, 2004), and/or regression to the mean. Participants reporting a desire to maintain or decrease their drinking initially reported heavier drinking at Time 1 than participants reporting a desire to increase their drinking, potentially supporting a regression to the mean hypothesis. On the other hand, a desire to increase drinking among lighter drinking individuals who perceive their peers as drinking more than themselves is consistent with an underlying assumption of social norm campaigns.

On average, intentions to increase drinking were not realized by college students in our sample. The lack of an increase in drinking between Time 1 and Time 2 among individuals desiring to increase should not be over-interpreted as we do not have information on experiences between Time 1 and Time 2. Additionally, about one-third of participants reported a change in their drinking desires, and it is impossible to know if the TLFB assessment of desired drinking truly reflects a desire to drink more or if it serves as a proxy for another variable such as leisure/social time. Situational and proximal assessments of behavioral intentions to drink alcohol and achieve intoxication may be more predictive of future behavior (Glindemann, Geller, \& Ludwig, 1996) than general and distal behavioral intentions assessed in the present study. Further, we assessed behavioral intentions for past drinking behavior rather than future behavior, potentially diluting the correspondence between intentions and behavior (Ajzen \& Fishbein, 1977).

Social norm campaigns have been widely implemented by college campuses in an effort to change perceptions of normative drinking and reduce college student drinking (Wechsler et al., 2003). However, it is unclear if these campaigns are consistently effective (Wechsler et al., 1994 and Borsari \& Carey, 2003), and if they are effective, there is little information concerning how they might work. A proposed assumption of social norm campaigns is that students who believe their peers drink heavily may increase their own drinking to match the perceived norm (Perkins, 2002b). Although we found no evidence that our college student participants who perceived their peers were heavier drinkers than themselves desired to increase their drinking, the fact that $91 \%$ of participants believed their close friends were heavier drinkers than themselves left us with limited power to detect differences. Further, among participants who perceived their peers consumed more alcohol than themselves, we found no evidence that a mere desire to increase drinking was realized across the following month.

The current research is limited by participant attrition (nearly 20\%), and a naturalistic, brief longitudinal, correlational design. Additionally, upperclassmen, non-Caucasians, students involved in the Greek system, and students living off campus were underrepresented.

Furthermore, drinking and perception variables were assessed exclusively with self-reports and the order of questionnaires was not counterbalanced. The use of collateral reports or a bogus 
pipeline procedure would increase confidence in the results. It is also important to note that different types of measures were used to assess actual and desired drinking (measured with the TLFB) in contrast to perception of peer drinking (measured with the DNRF). The TLFB asks for daily reports of drinking across a month, while the DNRF asks participants to report how much they believe their close group of friends drink across a "typical week".

Despite these limitations, the current study investigated drinking intentions, a variable not commonly assessed. A recent drug and alcohol abuse prevention study targeting adolescents found that prevention effects were mediated in part by behavioral intentions (Botvin, Griffin, Diaz, \& Ifill-Williams, 2001). The considerable percentage of students in both this and the Curtin et al. study (2000) that reported wanting to drink more than they consumed represents a challenge to programs designed to decrease heavy drinking among college students. College students likely hold positive expectancies for the effects of alcohol (DelBoca et al., 2004) and may experience positive (e.g., social), as well as negative, alcohol-related consequences (Park, 2004). It is, however, encouraging that despite the desire to increase drinking reported by many students, they did not, on average, achieve this goal one month later.

Suggestions for future research include examining the longitudinal course of the relationship between perceptions, behavioral intentions, and college student drinking. College student drinking is not stable across the school year and is highly dependent upon the environment (DelBoca et al., 2004). It would be beneficial to employ a staggered design that controlled for time and situational factors (e.g., holidays, exams), and to also assess perceived situational pressure to drink (Trockel et al., 2003), attitudes toward drinking (e.g., injunctive norms) and past drinking history (O' Callaghan et al., 1997 and Trafimow, 1996). It appears important to consider that situational demands, cognitions (e.g., attitudes toward drinking, self-serving biases, perceived pressure to drink), behavioral intentions, and personal drinking history may impact the effectiveness of positive norm campaigns. If students hold permissive, self-serving, or positive attitudes toward drinking they may not be deterred by the fact that they consume more alcohol than the average student.

\section{REFERENCES}

Ajzen \& Fishbein, 1977 I. Ajzen and M. Fishbein, Attitude-behavior relations: A theoretical analysis and review of empirical research, Psychological Bulletin 84 (1977), pp. 888-918.

Baer \& Carney, 1993 J.S. Baer and M.M. Carney, Biases in the perceptions of the consequences of alcohol use among college students, Journal of Studies on Alcohol 54 (1993), pp. 54-60.

Baer et al., 1991 J.S. Baer, A. Stacy and M. Larimer, Biases in the perception of drinking norms among college students, Journal of Studies on Alcohol 52 (1991), pp. 580-586.

Borsari \& Carey, 2003 B. Borsari and K.B. Carey, Descriptive and injunctive norms in college drinking: A meta-analytic integration, Journal of Studies on Alcohol 64 (2003), pp. 331-341. 
Botvin et al., 2001 G.J. Botvin, K.W. Griffin, T. Diaz and M. Ifill-Williams, Drug abuse prevention among minority adolescents: Posttest and one-year follow-up of a school-based preventive intervention, Prevention Science 2 (2001), pp. 1-13.

Clapp et al., 2003 J.D. Clapp, J.E. Lange, C. Russell, A. Shillington and R.B. Voas, A failed norms social marketing campaign, Journal of Studies on Alcohol 64 (2003), pp. 409-414.

Cronin, 1996 C. Cronin, Harm reduction for alcohol-use-related problems among college students, Substance Use and Misuse 31 (1996), pp. 2029-2037.

Curtin et al., 2000 L. Curtin, J. Gaukstern and D.M. Martz, College student drinking: A test of Bandura's model of self-regulation, Poster presented at the annual meeting of the Association for the Advancement of Behavior Therapy, New Orleans, LA (2000, November).

DeJong, 2002 W. DeJong, The role of mass media campaigns in reducing high-risk drinking among college students, Journal of Studies on Alcohol (2002) (Supplement 14), pp. 182-192.

DelBoca et al., 2004 F.K. DelBoca, J. Darkes, P.E. Greenbaum and M.S. Goldman, Up close and personal: Temporal variability in the drinking of individual college students during their first year, Journal of Consulting and Clinical Psychology 72 (2004), pp. 155-164.

Department of Health and Human Services, 2000 Department of Health and Human Services, Healthy people 2010: The cornerstone for prevention, U.S. Department of Health and Human Services, Rockville, MD (2000).

Engs et al., 1996 R.C. Engs, B.A. Diebold and D.J. Hanson, The drinking patterns and problems of a national sample of college students, 1994, Journal of Alcohol and Drug Education 41 (1996), pp. 13-34.

Glindemann et al., 1996 K.E. Glindemann, S.E. Geller and T.D. Ludwig, Behavioral intentions and blood alcohol concentration: A relationship for prevention intervention, Journal of Alcohol and Drug Education 41 (1996), pp. 120-134.

Haines \& Spear, 1996 M. Haines and S. Spear, Changing the perception of the norm: A strategy to decrease binge drinking among college students, Journal of American College Health 45 (1996), pp. 134-140.

Ham \& Hope, 2003 L.S. Ham and D.A. Hope, College students and problematic drinking: A review of the literature, Clinical Psychology Review 23 (2003), pp. 719-759.

Hingson et al., 2002 R.W. Hingson, T. Heeren, R.C. Zakocs, A. Kopstein and H. Wechsler, Magnitude of alcohol-related mortality and morbidity among U. S. college students ages 18-24, Journal of Studies on Alcohol 63 (2002), pp. 136-144.

Johannessen et al., 1999 K.J. Johannessen, C. Collins, B.M. Mills-Novoa and P. Glider, A practical guide to alcohol abuse and prevention: A campus case study in implementing social norms and environmental management approaches, Campus Health Service, Tuscon, University of Arizona (1999). 
Johnston et al., 2004 L.D. Johnston, P.M. O'Malley, J.G. Bachman and J.E. Schulenberg, Monitoring the future national survey results on drug use, 1975-2003, Vol. II: College students and adults ages 19-45, National Institute on Drug Abuse, Bethesda, MD (2004) NIH Publication No. 04-5508.

Kypri \& Langley, 2003 K. Kypri and J.D. Langley, Perceived social norms and their relation to university student drinking, Journal of Studies on Alcohol 64 (2003), pp. 829-834.

Larimer \& Cronce, 2002 M.E. Larimer and J.M. Cronce, Identification, prevention, and treatment: A review of individual-focused strategies to reduce problematic alcohol consumption by college students, Journal of Studies on Alcohol 63 (2002), pp. 148-164.

Larimer et al., 1997 M.E. Larimer, D.L. Irvine, J.R. Kilmer and G.A. Marlatt, College drinking and the Greek system: Examining the role of perceived norms for high-risk behavior, Journal of College Student Development 38 (1997), pp. 587-598.

O' Callaghan et al., 1997 F.V. O' Callaghan, D.C. Chant, V.J. Callan and A. Baglioni, Models of alcohol use by young adults: An examination of various attitude-behavior theories, Journal of Studies on Alcohol 58 (1997), pp. 502-507.

O'Hare, 1990 T.M. O'Hare, Drinking in college: Consumption patterns, problems, sex differences, and legal drinking age, Journal of Studies on Alcohol 51 (1990), pp. 536-541.

O'Malley \& Johnston, 2002 P.M. O'Malley and L.D. Johnston, Epidemiology of alcohol and other drug use among American college students, Journal of Studies on Alcohol (2002) (Supplement 14), pp. 23-39.

Park, 2004 C.L. Park, Positive and negative consequences of alcohol consumption in college students, Addictive Behaviors 29 (2004), pp. 311-321.

Perkins, 2002a H.W. Perkins, Surveying the damage: A review of research on consequences of alcohol misuse in college populations, Journal of Studies on Alcohol (2002) (Supplement 14), pp. 91-100.

Perkins, 2002b H.W. Perkins, Social norms and the prevention of alcohol misuse in collegiate contexts, Journal of Studies on Alcohol (2002) (Supplement 14), pp. 164-172.

Perkins \& Berkowitz, 1986 H.W. Perkins and A.D. Berkowitz, Perceiving the community norms of alcohol use among students: Some research implications for campus alcohol education programming, International Journal of Addictions 21 (1986), pp. 961-974.

Perkins et al., 1999 H.W. Perkins, P.W. Meilman, J.S. Leichliter, J.R. Cashin and C.A. Presley, Misperceptions of the norms for the frequency of alcohol and other drug use on college campuses, Journal of American College Health 47 (1999), pp. 253-258.

Perkins \& Wechsler, 1996 H.W. Perkins and H. Wechsler, Variation in perceived college drinking norms and its impact on alcohol abuse: A nationwide study, Journal of Drug Issues 26 (1996), pp. 961-974. 
Sherman et al., 1983 S.J. Sherman, C.C. Presson, L. Chassin, E. Corty and R. Olshavsky, The false consensus effect in estimates of smoking prevalence: Underlying mechanisms, Personality and Social Psychology Bulletin 9 (1983), pp. 197-207.

Sobell et al., 1986 M.B. Sobell, L.C. Sobell, F. Klajner, D. Pavan and E. Basian, The reliability of a timeline method for assessing normal drinker college students' recent drinker history: Utility for alcohol research, Addictive Behavior 11 (1986), pp. 149-161.

Trafimow, 1996 D. Trafimow, The importance of attitudes in the prediction of college students' intentions to drink, Journal of Applied Social Psychology 26 (1996), pp. 2167-2188.

Trockel et al., 2003 M. Trockel, S.S. Williams and J. Reis, Considerations for more effective social norms based alcohol education on campus: An analysis of different theoretical conceptualizations in predicting drinking among fraternity men, Journal of Studies on Alcohol 64 (2003), pp. 50-59.

Turrisi et al., 2000 R. Turrisi, K.K. Padilla and K.A. Wiersma, College student drinking: An examination of theoretical models of drinking tendencies in freshmen and upperclassmen, Journal of Studies on Alcohol 61 (2000), pp. 598-602.

Wechsler et al., 1994 H. Wechsler, A. Davenport, G. Dowdall, B. Moeykens and S. Castillo, Health and behavioral consequences of binge drinking in college: A national survey, Journal of American Medicine 272 (1994), pp. 1672-1677.

Wechsler et al., 2003 H. Wechsler, T.F. Nelson, J.E. Lee, M. Seibring, C. Lewis and R.P. Keeling, Perception and reality: A national evaluation of social norms marketing interventions to reduce college students' heavy alcohol use, Journal of Studies on Alcohol 64 (2003), pp. 484494. 